\title{
Intracellular disassembly and localization of a new P123-PEI-R13/DNA complex
}

\author{
Manman Zhu, Kehai Liu*, Qing Zhu, Shunsheng Chen, Hui Lv, Wenfang Zhao, Yuan Mao \\ and Jing $\mathrm{Hu}$ \\ Department of Biopharmaceutics, College of Food Science and Technology, Shanghai Ocean \\ University, Shanghai 201306, P.R. China
}

\begin{abstract}
The appropriate location and release of target gene is necessary for gene therapy. In our previous paper, a gene vector named P123-PEI-R13 has been successfully synthesized, and the physical characteristics and cellular trafficking of nanoparticle P123-PEI-R13/DNA has been explored explicitly, but little was known about its disassembly within cells. In order to investigate its intracellular disassembly, P123-PEI-R13/DNA complex was exposed to the different competitors (RNA, DNA, proteins) or different conditions of $\mathrm{pH}$ and osmolarity, DNA release was determined by gel electrophoresis. Meanwhile, confocal laser technology was used to locate the complex in cells. The results revealed that DNA, RNA and osmolarity could affect the stability of the complex obviously, especially RNA which exist in nucleus. In addition, the speed of DNA release decreased as the weight ratio of polymer increased. Images got by a confocal fluorescence microscope confirmed that after cell uptake, P123-PEI-R13 could translocate DNA into nucleus.
\end{abstract}

Keywords: P123-PEI-R13/DNA complex, disassembly, intracellular localization

\section{Introduction}

A new gene vector P123-PEI-R13 has been successfully synthesized in previous work and it was a degradable PEI derivate. Low molecular weight (LMW) polyethyleneimine (PEI) was first linked with P123, then a bifunctional peptide RGD-TAT (49-57) named R13 was adopted to modify the P123-PEI derivates so as to prepare the new polymer. The cationic polymer P123-PEI-R13 spontaneously forms nanoparticle with DNA that can be employed for gene delivery, it was demonstrated to be efficient in avß3-positive Hela cells and B16 cells in vitro and in vivo, and the intracellular trafficking also has been explored explicitly, but the dissociation mechanism of the complex in the cytoplasm are still being clarified [1]. Premature release of DNA from cationic polymer may expose DNA to nuclease activity, on the contrary, it will lead to low transfection efficiency if the release of DNA is too late $[2,3]$. This study investigated the intracellular disassembly and path of gene delivery system for cancer gene therapy with the purpose of improving current nonviral gene vectors.

In this paper, to investigate the release process of target gene, the stability of P123-PEI-R13/DNA complexes was evaluated by electrophoresed on $1 \%$ agarose gel. First, the complexes were incubated

\footnotetext{
*Corresponding author: Kehai Liu, Department of Biopharmaceutics, College of Food Science and Technology, Shanghai Ocean University, Shanghai 201306, China. Tel.: +086-21-61900388; Fax: +086-21-61900365; E-mail: khliu@shou.edu.cn.
} 
with various concentrations of DNA, RNA and protein solutions. In addition, P123-PEI-R13/DNA complexes were also incubated in hypertonic and acidic environments respectively with the purpose of stimulating the endosome process [4-6]. The polymer P123-PEI-R13 was labeled with FITC, and confocal microscopy was adapted to examine the intracellular location of P123-PEI-R13/DNA complex [7].

\section{Materials and methods}

\subsection{Materials}

Hochest 33258 and fluorescein isothiocyanate (FITC) were obtained from Sigma Aldrich (St Louis, MO). $4 \%$ paraformaldehyde was provided by Beijing Solarbio Science \& Technology Co. Ltd. NaCl, $\mathrm{NaOH}$, alcohol were obtained from China National Medicines Corporation Ltd. RPMI 1640 culture medium, fetal bovine serum (FBS), trypsin, ProLong ${ }^{\circledR}$ Gold antifade reagent and TRIzol reagent were purchased from Invitrogen (Carlsbad, CA). The plasmid pGL3-control was obtained from Promega (Madison, WI, USA), and it was amplified using Escherichia coli DH5 $\alpha$ and prepared using the Qiagen End-free Plasmid Mega Kit (Qiagen GmbH, Hilden, Germany). The purity of the purified and concentrated DNA was determined by measuring its ultraviolet absorbance at $260 \mathrm{~nm}$ and $280 \mathrm{~nm}$.

\subsection{Preparation of P123-PEI-R13/DNA complex}

Charge ratios of P123-PEI-R13/DNA were controlled by regulating weight ratio of P123-PEI-R13 and DNA. DNA solution and polymer solution were mixed to form self-assembly complexes with desired $w / w$ ratio. The complexes were allowed to stand at $4^{\circ} \mathrm{C}$ for $30 \mathrm{~min}$ before they were used in the next experiments. As our previous work, the particle size of these complexes was around 100-250 nm [1].

\subsection{Cell culture}

As the Hela cell lines (human cervical cancer cells) were adopted to investigate the physical characteristic and transfection efficiency of P123-PEI-R13 in our previous work, they were still employed in this paper [1]. They were grown in RPMI 1640 medium supplemented with $10 \%$ FBS. Cells were maintained at $37^{\circ} \mathrm{C}$ in $5 \% \mathrm{CO}_{2}$ humidified air atmosphere.

\subsection{Dissociation of the complex within cells}

After the cell endocytosis, the stability of the complex may be affected by many factors, such as the environment of endosome, the protein sensitive cytokine and nucleic acid existing in cytoplasmic and nucleus. P123-PEI-R13/DNA complexes at $w / w$ ratio of 5 and $w / w$ ratio of 20 were prepared according to 2.2. TRIzol reagent (Invitrogen, Carlsbad, CA, USA) was used to extract DNA, RNA and proteins from HeLa cell lines [8]. $10 \mu \mathrm{L}$ of different concentrations of DNA, RNA and proteins were individually mixed with $10 \mathrm{uL}$ of the complex. $10 \mu \mathrm{L}$ of different concentrations of $\mathrm{NaCl}$ and sodium citrate solution was also added in $10 \mu \mathrm{L}$ of the complex solution to form hypertonic and acidic environment respectively, with the purpose of stimulating the environment of endosome. The mixtures were electrophoresed on $1 \%$ agarose gel at $120 \mathrm{~V}$ for about $40 \mathrm{~min}$ in Tris-Acetate-EDTA (TAE) 
buffer. Then the gel was dyed with ethidium bromide for $15 \mathrm{~min}$ and photoed by an ultraviolet illuminator to show the DNA migration patterns $[9,10]$.

\subsection{Intracellular localization of the complex}

P123-PEI-R13 was dissolved in PBS (pH 9). FITC solution dissolved in DMSO was added dropwise to unlabeled polymer solution. The molar ratio of polymer and FITC taken was 10:1. The solution was incubated overnight at $4^{\circ} \mathrm{C}$ with continuous stirring in the dark. The labeled polymer solution was purified by HiTrap Desalting SephadexTM G-25 Superfine chromatographic column to remove the free FITC [11].

The complex solution containing $3 \mathrm{mg}$ of pGL3-Control was prepared by mixing FITC-labeled P123-PEI-R13 and pDNA. HeLa cells were seeded in 6-well plate in $2 \mathrm{~mL}$ of RPMI 1640 medium containing $10 \%$ FBS before transfection. After incubating for $24 \mathrm{~h}$, the cells were treated with the complex solution and further incubated for $5 \mathrm{~min}, 30 \mathrm{~min}, 4 \mathrm{~h}$ and $24 \mathrm{~h}$ respectively. Then, the cell grown medium was exchanged with fresh medium with $10 \%$ FBS. After $24 \mathrm{~h}$, the cells were fixed with $4 \%$ paraformaldehyde for 30 min, followed by incubation with Hoechst 33258 for 15 min after washed three times by $2 \mathrm{~mL}$ of PBS to stain the cell nucleus. Cover slips were mounted on glass slides with a drop of $0.1 \mathrm{M}$ of glycerine in PBS to keep the cells from drying out [12]. Images of treated cells were captured by a confocal fluorescence microscopic system (Olympus FV1000-IX81, Tokyo). A UV laser (405 nm excitation) was used to induce the blue fluorescence of Hoechst 33258 and an argon laser $(473 \mathrm{~nm})$ to excite the green fluorescence of FITC.

\section{Results and discussion}

\subsection{Effect of intracellular components and cellular environment on the stability of the P123-PEI-R13/DNA complex}

The complex was formed and allowed to mature for $10 \mathrm{~min}$, and then exposed to various competitors (RNA, DNA, proteins) or different conditions of $\mathrm{pH}$ and osmolarity [13]. The complex at w/w ratio of 5 was used to primarily examine the effects of these factors. Figure 1 showed that DNA, RNA and high salt affected particle stability obviously, but proteins and $\mathrm{pH}$ had any effect on the complex hardly. Further investigation of the effects of DNA, RNA and high salt were conducted with complexes at w/w ratio of 5 and 20, shown in Figures 2-4.

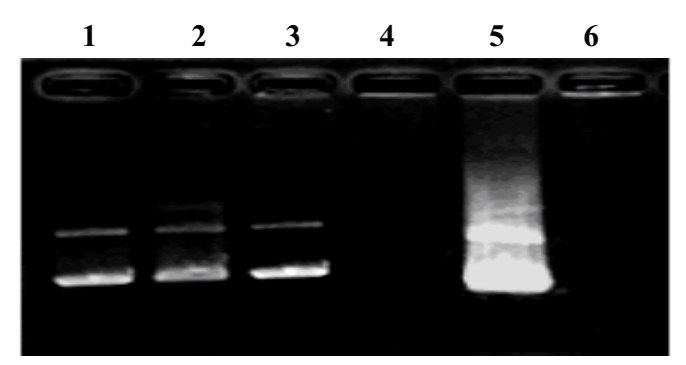

Fig. 1. Effects of five facors on the stability of P123-PEI-R13/DNA complex at w/w ratio of 5. 1. naked DNA; 2. Total RNA from Hela cells as a competitor at a concentration of $720 \mathrm{ng} / \mu \mathrm{L} ; 3$. High osmolarity in $2 \mathrm{M} \mathrm{NaCl} ; 4$. Low pH at 4-5; 5 . DNA from Hela cells as a competitor at a concentration of $720 \mathrm{ng} / \mathrm{mL} ; 6$. Protein from Hela cells as a competitor at a concentration of $150 \mathrm{mg} / \mathrm{mL}$. 


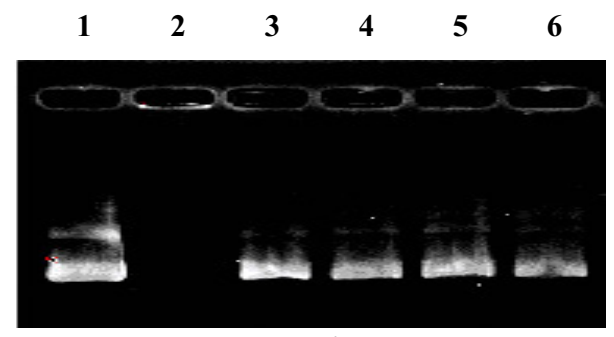

$w / w=5$

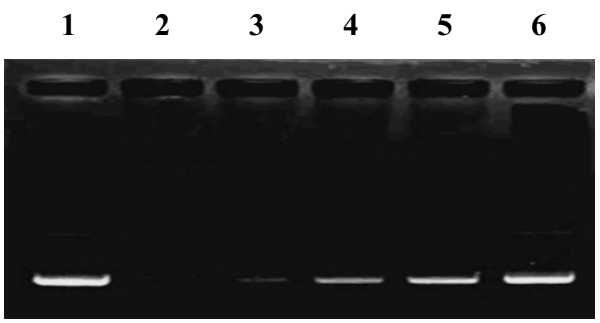

$w / w=20$

Fig. 2. Effect of different concentrations of RNA from Hela cells on the stability of P123-PEI-R13/DNA complex at w/w ratio of 5 and w/w ratio of 20 . 1 . naked DNA; 2. RNA as a competitor at a concentration of $45 \mathrm{ng} / \mu \mathrm{L} ; 3$. RNA as a competitor at a concentration of $90 \mathrm{ng} / \mu \mathrm{L} ; 4$. RNA as a competitor at a concentration of $180 \mathrm{ng} / \mu \mathrm{L} ; 5$. RNA as a competitor at a concentration of $360 \mathrm{ng} / \mu \mathrm{L} ; 6$. RNA as a competitor at a concentration of $720 \mathrm{ng} / \mu \mathrm{L}$.

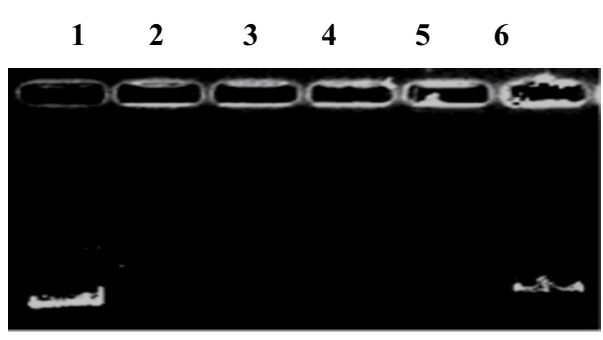

$w / w=5$

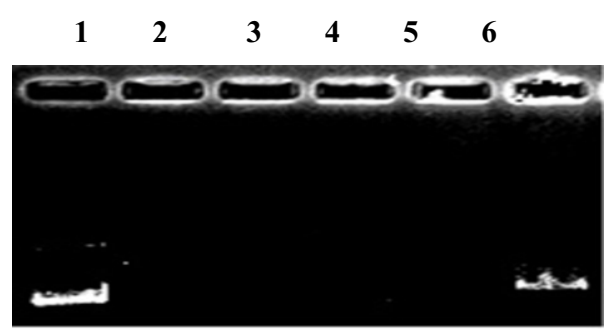

$w / w=20$

Fig. 3. Effect of different concentrations of DNA from Hela cells on the stability of P123-PEI-R13/DNA complex at w/w ratio of 5 and $\mathrm{w} / \mathrm{w}$ ratio of 20 . 1 . naked DNA; 2. DNA as a competitor at a concentration of $45 \mathrm{ng} / \mu \mathrm{L} ; 3$. DNA as a competitor at a concentration of $90 \mathrm{ng} / \mu \mathrm{L} ; 4$. DNA as a competitor at a concentration of $180 \mathrm{ng} / \mu \mathrm{L} ; 5$. DNA as a competitor at a concentration of $360 \mathrm{ng} / \mu \mathrm{L} ; 6$. DNA as a competitor at a concentration of $720 \mathrm{ng} / \mu \mathrm{L}$.

The complex was made at $w / w$ ratio of 5 and $w / w$ ratio of 20. The disassembly of the complex under the presence of DNA, RNA and high salt was determined by gel electrophoresis. In Figure 2, the addition of RNA resulted in rapid disassembly of the complex, $90 \mathrm{ng} / \mu \mathrm{L}$ of RNA could almost entirely dissociate the complex at $w / w$ ratio of 5, but RNA induced slower DNA release at $w / w$ ratio of 20 . In Figure 3, $45 \mathrm{ng} / \mu \mathrm{L}$ of DNA dissociated the complex partially at $w / w$ ratio of 5 , while $720 \mathrm{ng} / \mu \mathrm{L}$ of DNA just began to induce the DNA release at $w / w$ ratio of 20. In Figure 4, the presence of high salt yielded particle disassembly at the concentration of $1 \mathrm{M}$ of $\mathrm{NaCl}$ at $w / w$ ratio of $5,4 \mathrm{M}$ of $\mathrm{NaCl}$ began to dissociate the complex at $w / w$ ratio of 20 . The above results revealed that the presence of DNA, RNA and osmolarity resulted in disassembly of the complex in truth and the speed of DNA release decreased as the $w / w$ ratios increased, which could be the reason why transfection efficiency of high $\mathrm{w} / \mathrm{w}$ ration complex is higher. In addition, the dissociation of complexes induced by RNA was found to be much easier than DNA and osmolarity, it proved that P123-PEI-R13/pGL3-Control may release more completely with the aid of RNA if getting into the nucleus. The size of nucleopore is smaller than the complex, it could get into the nucleus through karyomitosis for transfection in vitro, but the quiescent cells are the target of gene therapy in vivo actually, so the transfection efficiency in vivo is much lower compared with in vitro [14-16]. Overall, we have good reason to believe the entry of plasmid DNA from the cytoplasm into the nucleus is one of the necessary directions to explore for non-viral gene transfer. 

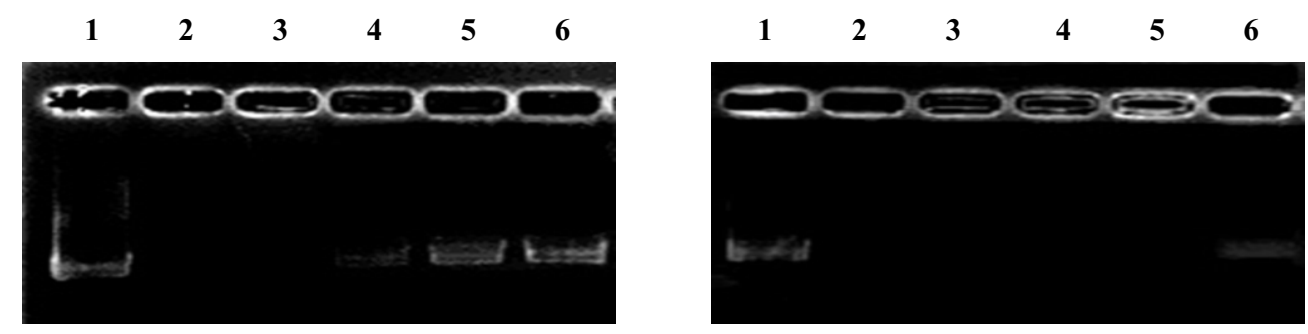

$w / w=5$

Fig. 4. Effects of changes in osmolarity on the stability of P123-PEI-R13/DNA complex at w/w ratio of 5 and w/w ratio of 20. 1. naked DNA; 2. Osmolarity in $0.2 \mathrm{M} \mathrm{NaCl} ; 3$. Osmolarity in $0.5 \mathrm{M} \mathrm{NaCl} ; 4$. Osmolarity in $1 \mathrm{M} \mathrm{NaCl} ; 5$. Osmolarity in $2 \mathrm{M}$ $\mathrm{NaCl}$; 6. Osmolarity in $4 \mathrm{M} \mathrm{NaCl}$.

1
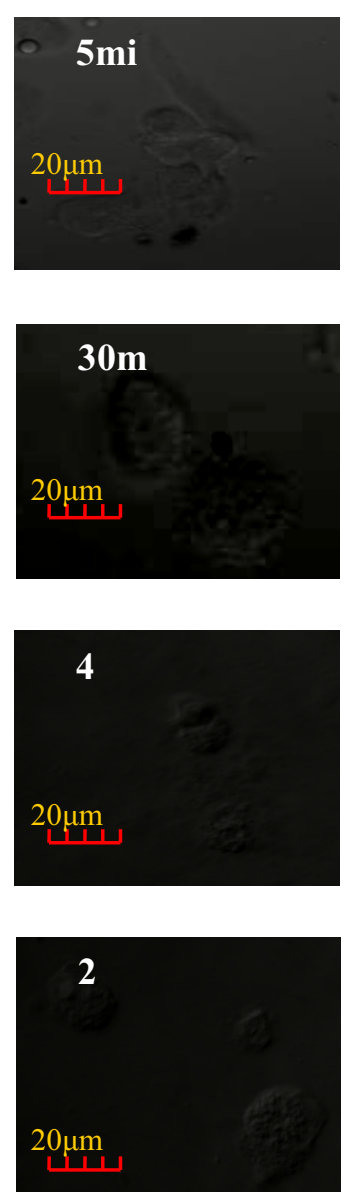

2
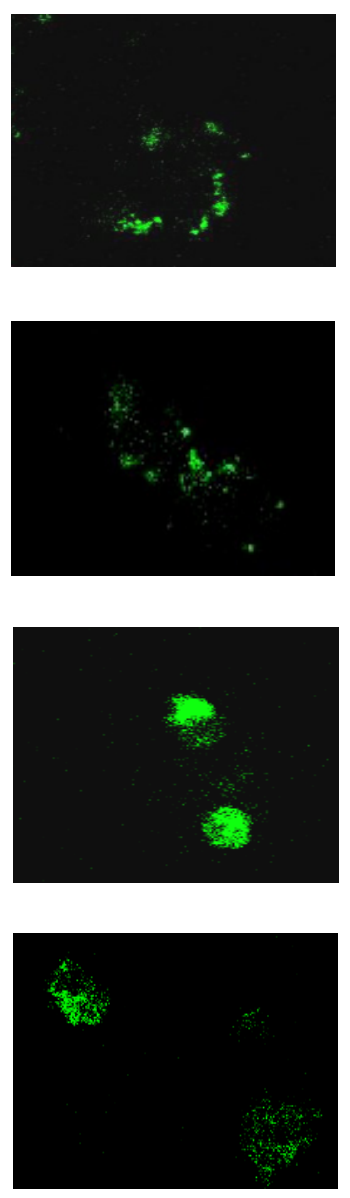

3
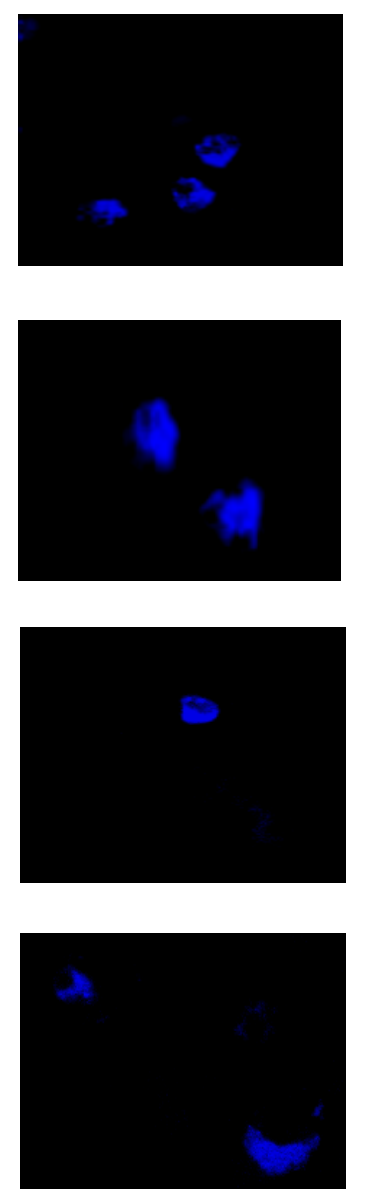

4
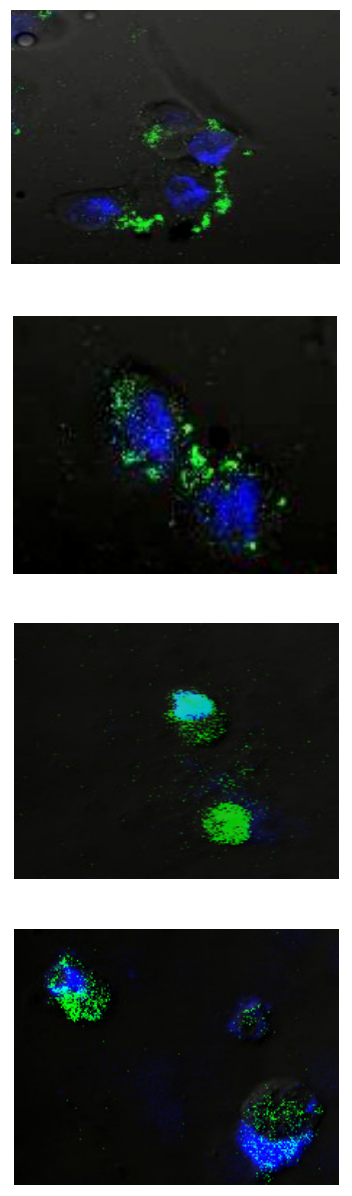

Fig. 5. Intra-cellular localization of FITC-labeled P123-PEI-R13 polyplexes (green) in Hela cells. Hoechst 33258 was used to stain the nucleus (blue). Cells were fixed after transfection and visualized by confocal microscopy. The image 1 was the respective transmitted light images, 2 was the labeled dendrimer, 3 was the cellular nucleus and 4 was the merged images. 


\subsection{Intracellular localization of the complex}

In order to confirm the cellular transport, P123-PEI-R13 labeled by FITC was complexed with pGL3-Control at $w / w$ ratio of 20 and incubated with HeLa cells for $5 \mathrm{~min}, 30 \mathrm{~min}, 4 \mathrm{~h}$ and $24 \mathrm{~h}$ respectively. Then intracellular localization of the complex was examined by laser confocal microscopy.

As was shown in Figure 5, the complex has come into cells but near to membranes after 5 min incubation. After $30 \mathrm{~min}$, a bit of the complexes were found inside the nucleus area which stained in blue. After $4 \mathrm{~h}$, large amounts of the complex came into cells and nucleus region. A partial of complex was still observed in the nucleus even after $24 \mathrm{~h}$. The results clearly indicated that after cell uptake, P123-PEI-R13 could translocate DNA into nucleus, which might lead to high transfection efficiency of the P123-PEI-R13/DNA complex.

\section{Conclusion}

In this paper, the intracellular disassembly and localization of P123-PEI-R13/DNA complex were investigated. P123-PEI-R13/DNA was proved to be sensitive to the effect of RNA, DNA and high osmolarity environment, especially the RNA. It was RNA that resulted in the disassembly of P123-PEI-R13/DNA complexes in the nucleus. Overall, it is reasonable to believe the entry of plasmid DNA from the cytoplasm into the nucleus is the premise of effectively transfect for non-viral gene transfer.

Images got by a confocal fluorescence microscope proved that after taking up by the cells, the complexes gradually reached the nucleus by $30 \mathrm{~min}$ incubation. As time goes on, more complexes concentrated in the nucleus.

\section{Acknowledgement}

This work was supported by National Natural Science Foundation, China under Grant No. 81001024 and Scientific Research Innovation Project of the Shanghai Municipal Education Commission under Grant No. 13 YZ097.

\section{References}

[1] K.H. Liu, X.Y. Wang, W. Fan, Q. Zhu, J.Y. Yang, S. Gao et al., Degradable polyethylenimine derivate coupled to a biofunctional peptide R13 as a new gene-delivery vector, Int. Journal Nanomedicine 7 (2012), 1149-1162.

[2] N. Hirokawa and R. Takemura, Biochemical and molecular characterization of diseases linked to motor proteins, Trends Biochem. Sci. 28 (2003), 555-565.

[3] C. Vaquette, S. Fawzi-Grancher, P. Lavalle et al., In vitro biocompatibility of different polyester membranes, Bio-Medical Materials and Engineering 4 (2006), 131-136.

[4] Y. Xu and F.C. Szoka Jr., Mechanism of DNA release from cationic liposome/DNA complexes used in cell transfection, Biochemistry 35 (1996), 5616-5623.

[5] I. Moret, J.E. Peris et a1., Stability of PEI-DNA and DOTAP-DNA complexes: effect of alkaline pH, heparin and serum, Journal of Controlled Release 1-2 (2001), 169-181.

[6] M. Bertschinger, G. Backliwal, A. Schertenleib, M. Jordan, D.L. Hacker and F.M. Wum, Disassembly of polyethylenimine-DNA particles in vitro: Implications for polyethylenimine-mediated DNA delivery, J. Controll Release 116 (2007), 96-104. 
[7] K. Ma, M.X. Hu, Y. Qi, J.H. Zou, L.Y. Qiu, Y. Jin et al., PAMAM-triamcinolone acetonide conjugate as a nucleus-targeting gene carrier for enhanced transfer activity, Biomaterials 30 (2009), 6109-6118.

[8] P.A. Kirkland, J. Busby, S. Stevens Jr. and J.A. Maupin-Furlow, TRIzol-based method for sample for sample preparation and isoelectric focusing of halophilic proteins, Anal. Biochem. 351 (2006), 254-259.

[9] T. Okuda, T. Niidome and H. Aoyagi, Cytosolic soluble proteins induce DNA release from DNA-gene carrier complexes, Journal of Controlled Release 2 (2004), 325-332.

[10] Y.-P. Ho, H.H. Chen, K.W. Leong and T.-H. Wang, Evaluating the intracellular stability and unpacking of DNA nanocomplexes by quantum dots-FRET, Journal of Controlled Release 1 (2006), 83-89.

[11] V.V.N.H. Didenko, Polyethyleneimine as a transmembrane carder of xuorescently labeled proteins and antibodies: Development and in vitro validation of a targeted delivery vehicle for DNA vaccines, Anal. Biochem. 344 (2005), $168-173$.

[12] F. Labat-Moleur, A.M. Steffan, C. Brisson et a1., An electron microscopy study into the mechanism of gene transfer with lipopolyamines, Gene Therapy 3 (1996), 1010-1017.

[13] K. Buyens, M. Meyer, E. Wagner et a1., Monitoring the disassembly of siRNA polyplexes in serum is crucial for predicting their biological efficacy, Journal of Controlled Release 4 (2010), 38-41.

[14] C. Brunot, L. Porsonnet, C. Lagneau et a1., Cytotoxicity of polyethyleneimine (PEI), precursor base layer of polyelectrolyte multilayer films, Biomaterials 28 (2007), 632-640.

[15] T.C. Lai, K. Kataoka and G.S. Kwon, Pluronic-based cationic block copolymer for forming pDNA polyplexes with enhanced cellular uptake and improved transfection efficiency, Biomaterials 32 (2011), 4594-4603.

[16] T.C. Lai, K. Kataoka and G.S. Kwon, Bioreducible polyether-based pDNA ternary polyplexes: Balancing particle stability and transfection efficiency, Colloids. Surf. B. Biointerfaces 99 (2011), 27-37. 